\title{
Is Kurjak Antenatal Neurodevelopmental Test Ready for Routine Clinical Application? Bucharest Consensus Statement
}

\author{
${ }^{1}$ Milan Stanojevic, ${ }^{2}$ Panos Antsaklis, ${ }^{3}$ Aida Salihagic Kadic, ${ }^{4}$ Maja Predojevic \\ ${ }^{5}$ Radu Vladareanu, ${ }^{6}$ Simona Vladareanu, ${ }^{7}$ Raul Moreira Neto
}

\begin{abstract}
Background: While two-dimensional ultrasound (2D US) is used only for the assessment of fetal startles and general movements, introduction of Kurjak antenatal neurodevelopmental test (KANET) by four-dimensional ultrasound (4D US) enabled assessment of not only movements but also some signs used in postnatal neurological assessment like cranial sutures, head circumference and finger movements of the hand for the detection of neurological thumb (adducted thumb in the clenched feast). Overall impression on general movement called by Prechtl 'Gestalt perception' is also a part of KANET assessment. These parameters cannot be assessed by 2D US, and according to our opinion they are making the difference enabling more accurate and functionally more reliable assessment of the young and immature CNS.

After Osaka standardization of KANET has been published, many studies on fetal behavior from different centers using this method have been conducted and published. Although there is lack of long-term follow-up of children who were assessed by KANET as fetuses, some conclusions on the usage of KANET test in clinical practice can be made. There are still inconclusive results of prenatal neurological assessment using KANET test in fetuses with borderline scores, although it was revealed that negative predictive value of the test as well as inter-observer reliability were satisfactory and acceptable.
\end{abstract}

\footnotetext{
${ }^{1}$ Associate Professor, ${ }^{2}$ Senior Lecturer, ${ }^{3}$ Professor, ${ }^{4,7}$ Lecturer ${ }^{5}$ Professor and Chairman, ${ }^{6}$ Associate Professor and Head

${ }^{1}$ Department of Obstetrics and Gynecology, Medical School University of Zagreb, 'Sveti Duh' Clinical Hospital; DIU Libertas International University, Zagreb, Croatia

${ }^{2}$ Department of Obstetrics and Gynecology, University of Athens Athens, Greece

${ }^{3}$ Department of Physiology, Croatian Institute for Brain Research Medical School, University of Zagreb, Zagreb, Croatia

${ }^{4}$ Department of Physiology, Medical School, University of Zagreb Zagreb, Croatia

${ }^{5}$ Department of Obstetrics and Gynecology, Carol Davila University of Medicine, Elias University Hospital, Bucharest, Romania

${ }^{6}$ Department of Neonatology, Carol Davila University of Medicine, Elias University Hospital, Bucharest, Romania

${ }^{7}$ Department of Fetal Medicine, Ecomoinhos-School and Clinic of Ultrasonography, Porto Alegre, Brazil

Corresponding Author: Milan Stanojevic, Associate Professor Department of Obstetrics and Gynecology, Medical School University of Zagreb, Sveti Duh Clinical Hospital, Sveti Duh-64, 10000 Zagreb, Croatia, Phone: ++38513712316, ++38513745534, e-mail: milan.stanojevic @optinet.hr
}

Conclusion: It can be concluded that KANET test can be used in everyday clinical practice for the follow-up of fetuses at neurological risk with the strong recommendation for strict and reliable multidisciplinary postnatal follow-up till the corrected age of at least 3 years and longer whenever appropriate. This will enable to make better correlation of prenatal KANET scores with postnatal neurodevelopmental outcomes.

Keywords: Cerebral palsy, Fetal behavior, Four-dimensional ultrasound, Kurjak antenatal neurodevelopmental test, Statement.

How to cite this article: Stanojevic M, Antsaklis P, Kadic AS, Predojevic M, Vladareanu R, Vladareanu S, Neto RM. Is Kurjak Antenatal Neurodevelopmental Test Ready for Routine Clinical Application? Bucharest Consensus Statement. Donald School J Ultrasound Obstet Gynecol 2015;9(3):260-265.

Source of support: Nil

Conflict of interest: None

\section{INTRODUCTION}

After Osaka standardization of Kurjak antenatal neurodevelopmental test (KANET) has been published, ${ }^{1}$ many studies on fetal behavior from different centers using this method have been conducted and published. ${ }^{2-26}$ Although there is lack of long-term follow-up of children who were assessed by KANET as fetuses, some conclusions on the usage of KANET test in clinical practice can be made. There are still inconclusive results of prenatal neurological assessment using KANET test in fetuses with borderline scores, although it was revealed that negative predictive value of the test as well as interobserver reliability were satisfactory and acceptable. It can be concluded that KANET test can be used in everyday clinical practice for the follow-up of fetuses at neurological risk with the strong recommendation for strict and reliable multidisciplinary postnatal followup till the corrected age of at least 3 years and longer whenever appropriate. ${ }^{27}$ This will enable to make better correlation of prenatal KANET scores with postnatal neurodevelopmental outcomes.

\section{Assessment of Fetal behavior by Two- (2D) and Four-dimensional (4D) Ultrasound}

It is obvious that ultrasound (either $2 \mathrm{D}$ or $4 \mathrm{D}$ ) can be used in the assessment of fetal behavior and that fetal behavioral patterns are reflecting the degree of development 
and maturation of central nervous system. ${ }^{28}$ Fetal movements were analyzed by $2 \mathrm{D}$ ultrasound and it has been revealed that assessment of fetal behavior in the specific periods of intrauterine life could make it possible to make distinction between normal and abnormal brain developmental patterns. ${ }^{28}$ It was detected by 2D ultrasound that onset of intrauterine embryonic and fetal active movements is much earlier than subjective feeling of them by the mother. ${ }^{28}$ When comparing assessment of fetal behavior by 2D and 4D US, than advantage of 4D is better depiction of fetal facial expressions in threedimensions (3D) with the possibility to assess them in almost real time with the new sophisticated ultrasound machines having fast frame rates. ${ }^{1-27}$ While $2 \mathrm{D}$ US is used only for the assessment of fetal startles and general movements, ${ }^{28}$ introduction of KANET test enabled assessment of not only movements but also some signs used in postnatal neurological assessment like cranial sutures, head circumference and finger movements of the hand for the detection of neurological thumb (adducted thumb in the clenched feast). ${ }^{1-27}$ Overall impression on general movement called by Prechtl 'Gestalt perception' is also a part of KANET assessment. ${ }^{29}$ These parameters can not be assessed by 2D US, and according to our opinion they are making the difference enabling more accurate and functionally more reliable assessment of the young and immature CNS. ${ }^{1-27}$

\section{Learning Curve, Applicability and Predictive Values of KANET}

According to yet unpublished data by Panos Antsaklis, it is needed to perform 80 KANET tests by experienced ultrasound specialist in order to assess fetus by 4D US in 20 minutes. He calculated that one need 10 to 15 cases in 7 days in order to learn the basics of the technique which can be reproducible. The number of tests is comparable with other ultrasound tests like nuchal translucency screening (40 tests by experienced ultrasound specialist) ${ }^{30}$ and anomaly scan (100-200 tests by experienced specialist). ${ }^{31}$ In the same study on the 1712 KANET tests performed on 655 patients, the success rate for the entire test ranged between 91 and 95\%. Success rate for the assessment of particular signs of the KANET was between $88 \%$ for isolated eye blinking and $100 \%$ for mouth opening and isolated leg movement. Kurjak antenatal neurodevelopmental test had almost $100 \%$ of the negative predictive value. Interobserver agreement between two examiners for different components of the KANET test were assessed by calculation of Kappa values which were lowest for the facial expression $(\mathrm{K}=$ 0.68 ) and highest for the finger movements $(\mathrm{K}=0.84){ }^{32}$ These unpublished data presented at the conference in Bucharest as oral presentation suggested that KANET test is a reliable method to be used with confidence in everyday clinical practice after appropriate education of experienced examiner. ${ }^{33}$

\section{The Possibility to Detect Postnatal Neurodevelopmental Disability by Assessment of Fetal Behavior}

Prechtl stated that assessment of general movements is a better predictor of postnatal neurological disability in neonates than clinical neurological examination alone. ${ }^{29}$ This means that postnatal neurological examination done by neonatologist is not sensitive and predictive enough for the future neurodevelopmental outcome. There is a report informing that among 7 years old with cerebral palsy (CP) 47\% had normal neurological examination as neonates. ${ }^{34}$ This discouraging fact prompted researchers to investigate this phenomenon from many aspects, and our group believed that introduction of KANET could be of some significance and help to solve at least part of this problem. But the problem with prenatal and postnatal neurodevelopment is that it is taking place in different environments: prenatal with microgravity and postnatal with so called tyranny of gravity. ${ }^{22}$ Sometimes intrauterine environment can be experienced by the fetus as hostile and unfriendly, and delivery at that moment could be foreseen as deliberation and even life-saving event. $^{22}$ Even if at that moment of assessment, KANET and postnatal neurological examination are borderline or even abnormal, it is not easy to make the prediction for the future neurodevelopment of that individual fetus and infant. This conclusion has been made on the grounds of the postnatal definition of $\mathrm{CP}$ as the most severe and long lasting non-progressive neurological disorder in childhood. ${ }^{35-37}$

\section{Is there a Problem with the Postnatal Diagnosis of Cerebral Palsy?}

The discussions on the diagnosis and definition of CP are on the debate for many years. ${ }^{35-37}$ Based on many cohort studies and registries some conclusions have been made and diagnostic criteria have been changed. ${ }^{27,35-37}$ Cerebral palsy has substantial lifelong effects on daily function, societal participation and quality of life for children and their families. ${ }^{27,35-37}$ Cerebral palsy registries have provided us with some understanding of the etiologies of CP and specific outcome studies. ${ }^{27,35-37}$ A recent systematic review investigating the rates of co-occurring impairments, diseases and functional limitations in $\mathrm{CP}$, concluded that for children diagnosed at 5 years of age: 3 in 4 were in pain; 1 in 2 had an intellectual disability; 1 in 3 could not walk; 1 in 3 had hip displacement; 1 in 4 could not talk; 1 in 4 had epilepsy; 1 in 4 had a behavior disorder; 1 in 4 had bladder control problems; 1 in 5 had a sleep 
disorder; 1 in 5 dribbled; 1 in 10 were blind; 1 in 15 were tube fed; and 1 in 25 were deaf. ${ }^{36}$ With a representative cohort of children with CP from eight European countries, children are classified according to brain injury diagnosed using magnetic resonance imaging (MRI). ${ }^{37}$ This group used a classification system based on the presumed timing and nature of the insult that resulted in $\mathrm{CP}$ and included both genetic and nongenetic etiologies, such as genetic cortical malformations and hypoxic ischemic injury. ${ }^{37}$ It is necessary to attempt to determine the underlying etiology/pathogenesis to confirm the suspicion of a static lesion, exclude a treatable disorder and diagnose a malformation, which may have significant genetic counseling implications for the family. ${ }^{38}$

One very important environmental factor influencing development of CP is inflammation, however, no overall association has been found between antibiotic prescribing in pregnancy and CP and/or epilepsy in childhood. ${ }^{38}$ However, an increased risk of CP or epilepsy associated with macrolide prescribing in pregnancy has been found, added to evidence that macrolide use in pregnancy was associated with serious harm. ${ }^{38}$ Pathogenic events impacting on the brain cause different patterns of structural abnormality in $\mathrm{CP}^{38}$ These pathogenic events may be environmental or genetic. Their consequences will depend not only on the nature of the event, but also the timing of the event during the different stages of brain development. ${ }^{38}$ The 1 st and 2 nd trimesters of pregnancy are the most critical times for cortical development and are characterized by the sequential yet overlapping steps of proliferation, migration and organization of neuronal cells and their connections. ${ }^{38}$ Brain pathology secondary to events during these stages of brain development is usually characterized by significant malformations. ${ }^{38}$ During the 3rd trimester, growth and differentiation events are predominant and persist into postnatal life. ${ }^{38}$

The limitation of many cohort studies of children with CP in Canada, the USA, and across Europe is the difficulty obtaining a representative sample and an entire cohort, while in Australia has been announced that there is the opportunity for undertaking entire prospective cohort based studies. ${ }^{27}$ There is limited data on motor trajectories of an entire cohort of children with CP from diagnosis at 18 to 36 months of age and these motor trajectories have not been correlated with MRI brain injury classification. For the present study, the age of 18 to 24 months for entry has been chosen as diagnosis is usually confirmed by this time. ${ }^{27}$ Children will be followed up till 5 years of age at school entry when motor outcome has been well classified. ${ }^{27}$ The preferred age for structural MRI is from 24 months because by this age myelination of the brain should be completed, thus allowing optimum differentiation between gray and white matter on MRI, important for the detection and correct classification of brain injuries and malformations. ${ }^{27,35}$

In conclusion, the problem of appropriate and timely diagnosis of $\mathrm{CP}$ is still the issue, although many diagnostic attempts have been made and some progress has been achieved.

\section{Is there a Possibility to improve the Outcome in Children with Neurodevelopmental Disorder by Introduction of Early Intervention?}

In order to improve the outcome of neonates with high neurological risk there are very few interventions available in everyday clinical practice. Application of KANET-prenatal neurodevelopmental test, may possibly increase the ability of clinicians to define neurorisk early enough to intervene postnatally by introduction of physiotherapy. It has been speculated for many years that early application of physiotherapy can be of some significance and that it can improve neurodevelopmental outcome. ${ }^{39}$ In Cochrane meta-analysis, it has been stated that early intervention programs for preterm infants have a positive influence on cognitive and motor outcomes during infancy, with the cognitive benefits persisting into pre-school age. ${ }^{39}$ There is a great deal of heterogeneity between studies due to the variety of early developmental intervention programs trialed and gestational ages of the preterm infants included, which limits the comparisons of intervention programs. ${ }^{39}$ Further research is needed to determine which early developmental interventions are the most effective at improving cognitive and motor outcomes and on the longer-term effects of these programs. ${ }^{39}$ In one of the programs the primary caregivers have been educated about evidence-based interventions for improving infant self-regulation, postural stability, coordination and strength, parent mental health, and the parent infant relationship. ${ }^{40} \mathrm{~A}$ therapy team consisting of a physiotherapist and psychologist delivered the 9 sessions of the program (each session was 1.5-2 hours long) in the family home over the infant's 1st year of life. Infants and their caregivers has selective long-term benefits, with caregivers experiencing fewer anxiety symptoms and lower odds of an anxiety disorder and preschoolers showing fewer internalizing behavior problems. ${ }^{40,41}$

\section{Criteria for Clinical Application of Screening Tests}

World Health Organization defined screening as 'the presumptive identification of unrecognized disease or defect by the application of tests, examinations, or other procedures which can be applied rapidly'.42 Screening 
tests sort out apparently well persons who probably have a disease from those who probably do not. A screening test is not intended to be diagnostic. ${ }^{42}$ Persons with positive or suspicious findings must be referred to their physicians for diagnosis and necessary treatment. ${ }^{42}$ In general, this definition has been taken to imply a relatively simple (though not necessarily unsophisticated) method of case-finding. ${ }^{42}$ It is questionable whether KANET is a test for screening the disease or condition. It has been developed in order to discriminate fetuses who are at neurological risk and those who are not. Those who are at neurological risk, could have many conditions and they do not necessarily need the treatment. As it was stated in the WHO document, while screening tests may well be used in population surveys, the principal aim of surveys is not to bring patients to treatment but to elucidate the prevalence, incidence and natural history of the variable or variables under study, though case-finding is a natural by-product of surveys. ${ }^{38}$ It is sometimes useful to use a term that refers to all forms of early detection whether by screening, physical examination or other means; and this is meant when the term 'early disease detection' has been used. ${ }^{42}$ If we look at the WHO original criteria for screening the disease, and apply them to the

Table 1: How WHO criteria for screening apply to the KANET test ${ }^{42}$

\begin{tabular}{|c|c|}
\hline Criteria for screening the disease & $\begin{array}{l}\text { How do they apply } \\
\text { to the KANET } \\
\text { test and detection } \\
\text { of disturbed } \\
\text { neurodevelopment }\end{array}$ \\
\hline $\begin{array}{l}\text { 1. The condition sought should be an } \\
\text { important health problem. }\end{array}$ & Yes/no \\
\hline $\begin{array}{l}\text { 2. There should be an accepted } \\
\text { treatment for patients with recognized } \\
\text { disease. }\end{array}$ & Yes/no \\
\hline $\begin{array}{l}\text { 3. Facilities for diagnosis and treatment } \\
\text { should be available. }\end{array}$ & Yes \\
\hline $\begin{array}{l}\text { 4. There should be a recognizable latent } \\
\text { or early symptomatic stage. }\end{array}$ & Yes \\
\hline $\begin{array}{l}\text { 5. There should be a suitable test or } \\
\text { examination. }\end{array}$ & Yes \\
\hline $\begin{array}{l}\text { 6. The test should be acceptable to the } \\
\text { population. }\end{array}$ & Yes/no \\
\hline $\begin{array}{l}\text { 7. The natural history of the condition, } \\
\text { including development from latent } \\
\text { to declared disease, should be } \\
\text { adequately understood. }\end{array}$ & Yes/no \\
\hline $\begin{array}{l}\text { 8. There should be an agreed policy on } \\
\text { whom to treat as patients. }\end{array}$ & Yes \\
\hline $\begin{array}{l}\text { 9. The cost of case-finding (including } \\
\text { diagnosis and treatment of patients } \\
\text { diagnosed) should be economically } \\
\text { balanced in relation to possible expen- } \\
\text { diture on medical care as a whole. }\end{array}$ & Yes/no \\
\hline $\begin{array}{l}\text { 10. Case-finding should be a continuing pro- } \\
\text { cess and not a 'once and for all' project. }\end{array}$ & Yes \\
\hline
\end{tabular}

KANET (Table 1), probably most of them are applicable to the KANET assessment and detection of disturbed intrauterine neurodevelopment. ${ }^{42}$

Answer to the five of the 10 questions is positive and on the other five it is inconclusive (neither positive nor negative), which means that more investigation is needed in order to use KANET test as a screening tool.

Before announcing KANET test as a screening tool we have to ask ourselves the same questions as authors of before mentioned paper did almost 50 years before, like. ${ }^{42}$ 1. What changes should be regarded as pathological and what should be considered physiological variations?

2. Are early pathological changes progressive?

3. Is there an effective treatment that can be shown either to halt or to reverse the early pathological changes?

Answer to the first question is positive, while to the second question the answer is not unequivocal, because some of the fetuses with abnormal KANET score can have normal neurodevelopmental outcome, which means that the changes found by the KANET are not progressivequite opposite. That means that the previous answer to the first question in terms of ultimate outcome was not correct. Therefore, one who is using KANET should be aware of such possibility. The answer to the third question is positive which means that by early intervention one can halt the pathological changes, but they probably can not be reversed. If KANET is considered as the screening test for detection of neurodevelopmental disability in fetal life, than it could be probably used as selective and multiple or multiphasic screening tool. ${ }^{42}$

\section{CONCLUSION}

At the end, it could be concluded that KANET is ready for use in everyday clinical practice after almost 10 years of its application as the investigational tool in many studies for normal and high risk fetuses. It has acceptable sensitivity and specificity, positive and negative predictive value and inter- and intra-observer reliability. There is still one huge limitation to use KANET on clinical basis which is cost of the equipment and need for education of the medical professionals how to perform it practically. Good news is that equipment costs could be decreased quickly, but it is not in the interest of the producers to spread out the method of $4 \mathrm{D}$ US by lower costs of sophisticated equipment. Bad news is that not many medical practitioners are educated to use the sophisticated $4 \mathrm{D}$ US equipment only for medical indications, avoiding its commercial use. We hope that in the near future KANET could become a good screening tool for the selective screening of the fetuses with moderate and high neurological risk. It is still not easy to answer the question how application of KANET will affect the diagnosis and incidence of the huge group of heterogeneous, 
non-progressive neurological disorders defined as CP. More studies are needed to answer this complicated and challenging question.

\section{REFERENCES}

1. Stanojevic M, Talic A, Miskovic B, Vasilj O, Shaddad AN, Ahmed B, Kadic AS, Predojevic M, Vladareanu R, Lebit D, et al. An attempt to standardize Kurjak's Antenatal Neurodevelopmental Test: Osaka Consensus Statement. Donald School J Ultrasound Obstet Gynecol 2011;5(4):317-329.

2. Neto RM. KANET in Brazil: first experience. Donald School J Ultrasound Obstet Gynecol 2015;9(1):1-5.

3. Bellinger SA, Lucas D, Kleven GA. An ecologically relevant guinea pig model of fetal behavior. Behav Brain Res 2015 Apr 15;283:175-183.

4. Kurjak A, Antsaklis P, Stanojevic M. Fetal neurology: past, present and future. Donald School J Ultrasound Obstet Gynecol 2015;9(1):6-29.

5. Luetic AT. First experience in clinical application of KANET. Donald School J Ultrasound Obstet Gynecol 2015;9(1):96-99.

6. Vasilj O. Is in utero fetal neurological assessment comparible to postnatal neurological assessment? Donald School J Ultrasound Obstet Gynecol 2015;9(1):91-95.

7. Stanojevic M. Antenatal and postanatal assessment of neurobehavior: which one should be used? Donald School J Ultrasound Obstet Gynecol 2015;9(1):67-74.

8. Lebit FD, Vladreanu DR. The role of $4 \mathrm{D}$ ultrasound in the assessment of fetal behavior. Maedica (Buchar) 2011Apr; 6(2):120-127.

9. Tomasovic S, Predojevic M. Four-dimensional ultrasound medical devices for recent advances on the etiology of cerebral pasy. Acta Inform Med 2011;19(4):228-234.

10. Vladareanu R, lebit D, Constantinescu S. Ultrasound assessment of fetal neurobehavior in high-risk pregnancies. Donald School J Ultrasound Obstet Gynecol 2012;6(2):132-147.

11. Honemeyer U, Talic A, Therwat A, Paulose I, Patidar R. The clinical value of KANET test in studying fetal neurobehavior in normal and at-risk pregnancies. J Perinat Med 2013;41(2):187-197.

12. Kuno A, Akiyama Nm Yashimoto $C$, Tanaka $H$, Yanagihara $T$, Hata T. Three-dimensional sonographic assessment of fetal behavior in the early second trimester of pregnancy. J Ultrasound Med 2011;20(12):1271-1275.

13. Salihagic Kadic A. Fetal neurology: the role of fetal stress. Donald School J Ultrasound Obstet Gynecol 2015;9(1):30-39.

14. Hata T, Kanenishi J, Hanoka U, Uematsu R, Marumo G, Tanaka H. HDlive study of fetal development and behavior. Donald School J Ultrasound Obstet Gynecol 2014;8(3):250-265.

15. Reynoso C, Crespo-Eguílaz N, Alcázar JL, Narbona J. Motor behavior of human fetuses during the second trimester of gestation: a longitudinal ultrasound study. An Pediatr (Barc) 2015;82(3):183-191.

16. Predojević M, Talić A, Stanojević M, Kurjak A, Salihagić Kadić A. Assessment of motoric and hemodynamic parameters in growth restricted fetuses-case study. J Matern Fetal Neonatal Med 2014;27(3):247-251.

17. Kurjak A, Talic A, Stanojevic M, Honemeyer U, Serra B, PratsP, Di Renzo GC. The study of fetal neurobehavior in twins in all three trimesters of pregnancy. J Matern Fetal Neonatal Med 2013;26(12):1186-1195.

18. Kurjak A, Talic A, Honemeyer U, Stanojevic M, Zalud I. Comparison between antenatal neurodevelopmental test and fetal Doppler in the assessment of fetal well being. J Perinat Med 2013;41(1):107-114.

19. Athanasiadis AP, Mikos T, Tambakoudis GP, Theodoridis TD, Papastergiou M, Assimakopoulos E, Tarlatzis BC. Neurodevelopmental fetal assessment using KANET scoring system in low and high risk pregnancies. J Matern Fetal Neonatal Med 2013;26(4):363-368.

20. Guimarães Filho HA, Araujo Júnior E, Mello Júnior CF, Nardozza LM, Moron AF. Assessment of fetal behavior using four-dimensional ultrasonography: current knowledge and perspectives. Rev Assoc Med Bras 2013;59(5):507-513.

21. Kurjak A, Stanojević M, Predojević M, Laušin I, SalihagićKadić A. Neurobehavior in fetal life. Semin Fetal Neonatal Med 2012;17(6):319-323.

22. Stanojevic M, Zaputovic S, Bosnjak AP. Continuity between fetal and neonatal neurobehavior. Semin Fetal Neonatal Med 2012;17(6):324-329.

23. Kurjak A, Predojevic M, Stanojevic M, Kadic AS, Miskovic B, Badreldeen A, Talic A, Zaputovic S, Honemeyer U. Intrauterine growth restriction and cerebral palsy. Acta Inform Med 2012;18(2):64-82.

24. Talic A, Kurjak A, Stanojevic M, Honemeyer U, Badreldeen A, DiRenzo GC. The assessment of fetal brain function in fetuses with ventrikulomegaly: the role of the KANET test. J Matern Fetal Neonatal Med 2012;25(8):1267-1272.

25. Talic A, Kurjak A, Ahmed B, Stanojevic M, Predojevic M, Kadic AS, Di Renzo GC. The potential of 4D sonography in the assessment of fetal behavior in high-risk pregnancies. J Matern Fetal Neonatal Med 2011;24(7):948-954.

26. Hepper PG, Dornan JC, Lynch C, Maquire JF. Alcohol delays the emergence of the fetal elicited startle response, but only transiently. Physiol Behav 2012;107(1):76-81.

27. Boyd RN, Jordan R, Pareezer L, Moodie A, Finn C, Luther B, Arnfield E, Pym A, Craven A, Beall P, et al. Australian Cerebral Palsy Child Study: protocol of a prospective population based study of motor and brain development of preschool aged children with cerebral palsy. BMC Neurol 2013;13:57.

28. Visser GH, Mulder EJ, Tessa Ververs FF. Fetal behavioral teratology. J Matern Fetal Neonatal Med 2010;23(Suppl 3):14-16.

29. Prechtl HF, Einspieler C. Is neurological assessment of the fetus possible? Eur J Obstet Gynecol 1997;75(1):81-84.

30. Yang X, Chen M, Wang HF, Leung TY, Borenstein M, Nicolaides K, Sahota DS, Lau TK. Learning curve in measurement of fetal frontomaxillary facial angle at 11 to 13 weeks of gestation. Ultrasound Obstet Gynecol 2010;35(5):530-534.

31. Taipale P, Ammälä M, Salonen R, Hiilesmaa V. Learning curve in ultrasonographic screening for selected fetal structural anomalies in early pregnancy. Obstet Gynecol 2003;101(2): 273-278.

32. Viera AJ, Garrett JM. Understanding interobserver agreement: the Kappa statistic. Fam Med 2005;37(5):360-363.

33. Antsaklis P, Kurjak A, Izetbegovic S. Functional test for fetal brain: role of KANET test. Donald School J Ultrasound Obstet Gynecol 2013;7(4):385-399.

34. Palmer FB. Strategies for the early diagnosis of cerebral palsy. J Pediatr 2004;145(Suppl 2):S8-S11.

35. Bax MC, Tydeman C. European cerebral palsy study. Dev Med Child Neurol 2003;45 (Suppl 95):23.

36. Novak I, Hines M, Goldsmith S, Barclay R. Clinical prognostic messages from a systematic review on cerebral palsy. Pediatr 2012;130(5):e1285-1312. 
37. Bax M, Tydeman C, Flodmark O. Clinical and MRI Correlates of Cerebral Palsy: The European Cerebral Palsy Study. JAMA 2006;296(13):1602-1608.

38. Meeraus WH, Petersen I, Gilbert R. Association between antibiotic prescribing in pregnancy and cerebral palsy or epilepsy in children born at term: a cohort study using the health improvement network. PLoS One 2015;10(3):e0122034.

39. Spittle A, Orton J, Anderson P, Boyd R, Doyle LW. Early developmental intervention programmes post-hospital discharge to prevent motor and cognitive impairments in preterm infants. Cochrane Database Syst Rev 2012;12:CD005495.
40. Spencer-Smith MM, Spittle AJ, Doyle LW, Lee KJ, Lorefice L, Suetin A, Pascoe L, Anderson PJ. Long-term benefits of homebased preventive care for preterm infants: a randomized trial. Pediatr 2012;130(6):1094-1101.

41. Hilderman CG, Harris SR. Early intervention post-hospital discharge for infants born preterm. Phys Ther 2014;94(9): 1211-1219.

42. Wilson, JMG, Jungner, G. Principles and practice of screening for disease [Internet]. Geneva: World Health Organization; 1968. Available at: http://whqlibdoc.who.int/php/who_ php_34.pdf. 